\title{
МАРКЕТПЛЕЙСЫ КАК ФАКТОР ПРОГРЕССИВНОЙ ТРАНСФОРМАЦИИ ИНТЕРНЕТ-ТОРГОВЛИ В РОССИИ: ЛОГИСТИЧЕСКИЙ АСПЕКТ
}

\author{
(C) 2019 Михайлюк Михаил Владимирович \\ кандидат экономических наук, доцент \\ Ростовский государственный университет путей сообщения (РГУПС), Россия, Ростов-на-Дону \\ E-mail:mihailuk.m@gmail.com
}

В статье автор раскрывает основные тенденции современного рыночного созревания и эволюционного развития маркетплейсов в России, важным компонентом роста которых выступает логистика. Современная институционализация отечественных маркетплейсов имеет ряд релевантных параллелей со стратегиями построения логистики зарубежных торговых площадок, например Amazon. Обобщение этих сравнений и трендов развития цифровой логистики выводит автора на более объемные выводы относительно дальнейшего развития теории логистики.

Ключевые слова: торговая площадка, маркетплейс, цифровая логистика, онлайн-ритейл, офлайн-ритейл, потребительский рынок, многоканальная торговля.

Современная трансформация многоканальной торговли сегодня характеризуется более активным развитием маркетплейсов, которые обеспечивают значительное увеличение продаж через торговую площадку [5, с.85].

С точки зрения научного толкования изменений в конфигурации современного сбыта, можно констатировать, что переход от офлайна к онлайну сопровождается усложнением уже самой Интернет-торговли, в которой эмпирически оформляется многовариантная альтернатива многоканального сбыта: через свой интернет-магазин или торговую площадку.

При этом, реальная рыночная практика формирует более сложные примеры, которые затрудняют в научно-теоретическом плане строгое разделение различных каналов продаж и цифровых платформ по их экономической результативности и стратегическим перспективам развития.

В частности, неверным будет априори категорично констатировать, что с точки зрения реального уровня развития маркетплейсы являются наиболее совершенной формой организации сбыта в цифровой среде. Равным образом не имеет простого толкования вопрос о значении размера комиссии площадки [9, с.108-109]:

- Ozon и Wildberries берут высокую комиссию, но обеспечивают большой оборот;

- Wildberries делает дополнительную скидку для покупателя за счет маржи, но в 2019 г. уже уходит от этой практики.

Между тем, маркетплейсы имеют разные правила работы с поставщиками, плохо автоматизированные процессы управления продажами, в силу чего более надежной гарантией хорошего маркетинга и продвижения становится сам товар.

Заметим, что мере дальнейшего развития логистики и сервисов, будет меняться и сама модель ценообразования площадок. Так, комиссия будет зависеть от веса и габаритов, что определяет стоимость хранения и доставки - сегодня такой прямой привязки нет.

Поэтому на текущий момент нет оснований как-то особенно позиционировать или жестко дифференцировать отдельные каналы и форматы сбыта в цифровой среде. По мере их эволюционирования, естественно-рыночным путем, но не стихийно, сформируются более релевантные причины и основания для такого разделения, которое получит отражение в том числе на уровне его научно-практического толкования. За это же время более оформленной станет и операционная модель маркетплейса. Возможно каким-то образом изменится «Яндекс.Маркет», который сегодня нельзя назвать маркетплейсом в чистом виде - это рекламная площадка, в которой логистическая функция исполнения заказа лежит на рекламодателе.

Тем не менее, на потребительском рынке происходит активное развитие онлайн-ритейла, появление новых торговых площадок, которые имеют различные операционные модели работы с поставщиками, систему построения логистики и сервисов. В российской Интер- 
нет-торговле преобладают две основные модели маркетплейсов:

- первая опирается на самостоятельное развитие фулфилмента и построение собственной логистической инфраструктуры. По этому пути развития идет Ozon и Wildberries, которые активно инвестируют в склады и распределительные центры, развивают широкую географию пунктов выдачи заказов. Аналогичная стратегия роста на перспективу анонсирована «Беру», который также стремиться максимально контролировать логистические процессы обработки заказов и доставки;

- вторая основывается на аутсорсинге, например в Goods (М. Видео). Он делегирует логистические функции сторонним провайдерам, которые собирают товар со складов поставщиков и доставляют его потребителю [8].

На рынке происходит увеличение числа маркетплейсов, которые активно инвестируют в привлечение покупательского трафика, создают более преференциальные условия работы для поставщиков, но при этом имеют достаточно дифференцированные условия партнерства и сервисно-логистическую систему бизнес-процессов.

В современный период доминирование маркетплейсов в отдельных товарных категориях позволяет им, тем не менее, диктовать поставщикам более жесткие условия, что отчасти повторяет сценарий развития российской стационарной торговли, в которой эволюционно нарастающее давление торговых сетей на производителя сформировало одну из осей структурного неравновесия экономики, которая сохраняется и поныне [6].

В Интернет-торговле расширение рыночной власти маркетплейсов, их активное развитие приводит к тому, что они занимают доминирующее положение в отдельных товарных категориях, например Ozon и Wildberries с широким ассортиментом в одежде косметике, автотоваpax, что позволяет им диктовать свои условия поставщикам. Этот диктат (лучшая цена, скидки) может ослабить, например переход «Беру» или «Goods» к продажам в категориях одежды и обуви.

Тем не менее, как показывает исследование, на текущем этапе мы будем наблюдать очередной этап более жесткой конкурентной борьбы маркетплейсов и передел рынка, в ходе которого торговые площадки должны предлагать постав- щикам более преференциальные условия работы, и, снижать комиссию.

В начале 2019 г. Wildberries снизил комиссию с 38\% до 19\%. «Юлмарт» еще больше снизил нижний порог комиссии с 7\% до 4\%, предлагая бесплатную возвратную логистику и работая по модели прямого доступа покупателя к товару (D2C) все еще за счет маркетплейса. Ставки «Беру» варьируются от 5\% до 13\%. В среднем на конец 2018 г. уровень комиссии на рынке варьировался в диапазоне от 3\% до 38\% в разных маркетплейсах с учетом категории товара и др. [9, с.109].

Важно отметить, что Wildberries имея более сильный логистический сервис, предлагает более сложную систему коммерческого предложения (затраты на маркетинг и доставку зависят от качества товара, то есть оборачиваемости) исходя из присущей ему структуры логистических мощностей, которая не является идентичной по отношению к другим маркетплейсам.

Сегодня эта конкуренция является все еще не равной. Это позволяет Wildberries держать высокую маржу и строить систему логистики, в которой риски и работа по отбору востребованного ассортимента, будут постепенно частично перекладываться на поставщиков. В более длинной перспективе, ужесточение конкуренции площадок, вероятно, ослабит этот тренд.

В контексте настоящего анализа для эмпирически артикулированного углубления видения современных процессов трансформации цифровой логистики в России как инфраструктурно-сервисной основы развития Интернет-торговли и ее укрупнения, важно провести релевантные параллели в институционализации логистики онлайн-ритейла в России и мире $[5,10]$.

Необходимость такого аналитического отступления продиктована тем, что в основе рыночных и коммерческих амбиций отечественных маркетплейсов лежит успех их западных и азиатских аналогов, повторение траектории развития которых в России отражается, в том числе на уровне логистической стратегии российских площадок.

Вектор на выстраивание самостоятельной логистики является характерным как для лидеров западной цифровой торговли, так и восточной. Amazon сделал многомиллиардные инвестиции в открытие фулфилмент-центров, формируя новый логистический стандарт в отрасли, равно как Alibaba Group с логистическим 
проектом Cainiao, смог выйти за пределы китайского рынка.

Тем не менее, построение логистики российскими торговыми площадками происходит преимущественно по американской, чем китайской модели. Примером, верифицирующим эту логику, являются инвестиции «Яндекса» в размере полумиллиарда рублей в логистический комплекс для маркетплейса «Беру» в Ростовской области. «Сбербанк» по-прежнему вынашивает идею выдачи заказов в своих отделениях. Все это де факто копирует западную модель развития инфраструктуры цифровой логистики. Для азиатских маркетплейсов приоритетным является поиск партнеров на местах, что позволяет обеспечить конкурентные сроки доставки при низкой цене. Как показывает анализ развития экосистемы логистики маркетплейсов в России, именно по этой схеме AliExpress заходил в Россию, опираясь на «Почту России» как своего основного партнера [5].

Опираясь на такую фактографию, можно априори оценить потенциал и перспективы трансформации цифровой логистики в России в 2020-2025 гг. Итак, сегодня для торговых площадок и интернет-магазинов характерно неодинаковое развитие цифровой логистики:

- Ozon и Wildberries имеют логистически более сильную операционную модель, в основе которой лежит развитие фулфилмента и автономной логистической инфраструктуры через инвестиции в свои склады, РЦ и пункты самовывоза с широкой географией по всей стране;

- логистическая стратегия роста Goods, запущенного «М. Видео» опирается на передачу части логистических функций сторонним партнерам.

Отсюда, их неодинаковая привлекательность для поставщиков, и, разная скорость роста масштабирования. В современных исследованиях мы многократно акцентируем внимание на логистике как барьере входа на рынок [7]. Сегодня, эта «конкурентная функция» логистики в условиях ужесточения конкуренции превращает ее в важнейший фактор ускорения или замедления расширения географии продаж.

Так, маркетплейс Goods, при ограниченности собственных ресурсов и малой скорости роста, вероятно, будет относительно медленно расширять географию продаж. Это ограничит прибылеобразующую функцию маркетплейса, доставка которого после ее запуска охватывала
90 городов европейской части России.

В целом, обобщая особенности моноканальных и многоканальных цепей поставок, не менее важным будет выделить специфику и сложности современной и будущей трансформации логистической инфраструктуры последних.

В 2000-х гг. развитие традиционной торговли сопровождалось активными инвестициями в логистику и ее инфраструктуру со стороны форматированной розницы, то есть торговых сетей. До 2008 г. и даже вплоть до девальвации конца 2014 г. мы имели быстрорастущий рынок, на котором вполне прижилась и гармонично существовала модель спекулятивного складского девелопмента. Это обеспечивало активное развитие логистической инфраструктуры, предложение объектов которой на рынке было в профиците. Уже потом получили развитие схемы адресного строительства складов «built-to-suit» как вариант антикризисной адаптации рынка к сужению спроса и возрастанию доли вакантных площадей, не адсорбированных сжимающимся рынком.

В условиях менее стабильного спроса, доминирования сберегательной модели потребления на уровне домохозяйств, жесткой конкуренции в Интернет-торговле, между онлайн- и офлайн-торговлей, различиями в ресурсной базе роста отдельных торговых операторов и площадок будет иметь место дивергенция стратегий их логистического развития.

Если объемно выделить знаковые тренды в рыночном эволюционировании цифровой логистики, следует акцентировать внимание на следующее:

- крупные маркетплейсы будут активно инвестировать в собственную логистику, наращивая это конкурентное преимущество и обращаясь к помощи больших логистических провайдеров;

- развитие торговых площадок породит сильных конкурентов для фулфилмент-операторов, а также «последней мили»: здесь мы неизбежно увидим пересмотр стандартов работы служб доставки, процессы консолидации более мелких операторов, интеграцию с фулфилмент-операторами, включение в сервис «первой мили» и т.д. На схеме рис. 1 часть этих изменений выделена более выпукло;

- современный опыт Ozon и других площадок показывает, что автономные логистические подразделения функциональны преимуще- 


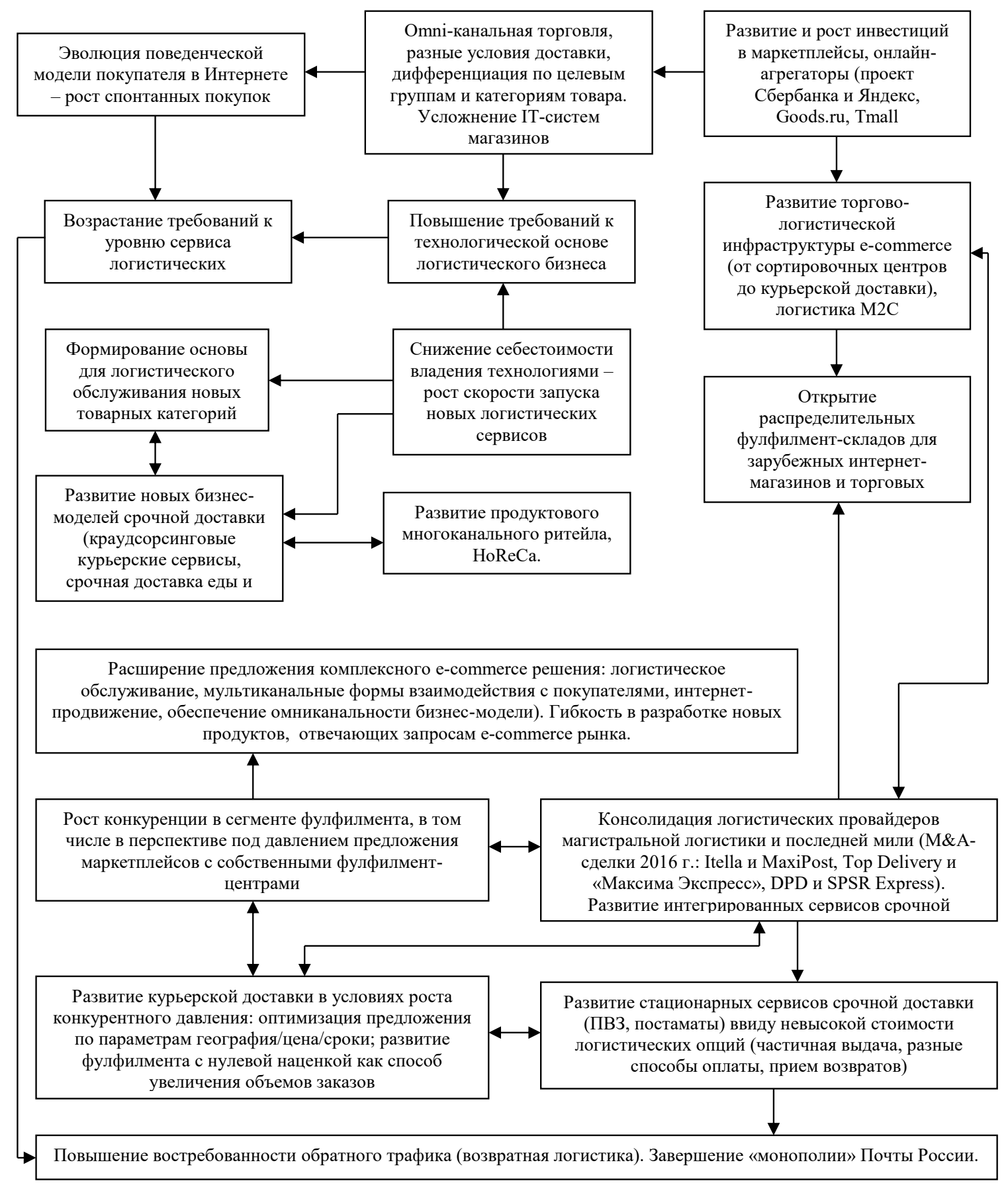

Puc. 1. Развитие фулфилмента и логистики последней мили в России

ственно для реализации задач внутренней логистики, тогда как их разворот в сторону аутсорсинга не дает значительной прибыли. Отсюда, бизнес-модель маркетплейсов может быть ограничена в возможностях дополнительной монетизации через логистику.

Таким образом, обобщая основные выводы, можно резюмировать следующее.

Современная трансформация онлайн-ритейла в России характеризуется его укрупнением и активным развитием сервисно-логистического компонента, который становится важным инструментом достижения конкурентных преимуществ. Институционализация Интернет-торговли отчасти повторяет сценарий развития стационарной розницы, в которой расширение сетевых форм организации бизнеса на потребительском рынке также привело к монополизации сбыта со стороны торговых сетей.

С точки зрения научного логистического знания, развитие Интернет-торговли формирует эмпирически более сложные и интересные паттерны, теоретический разбор которых будет стимулировать концептуализацию более слож- 
ной теории логистики. Ее развитие в перспективе должно опираться на синтез законченных концепций развития многоканальной торговли, а также расширенную практику наработки прикладного инструментария логистического управления многоканальным сбытом.

В современный период повышение релевантности логистики в системе Интернет-торговли приводит к изменению модели ценообразования маркетплейсов, которые снижают цену на товар и дифференцированно выделяют стоимость доставки, которая не будет бесплатной (Wildberries, Ozon). То есть, логистика формирует отдельный блок ценообразования в условиях ужесточения ценовой конкуренции и максимально точной и гибкой привязки цены товара к реальному объему логистических транзакций.

Наращивание инвестиций российских маркетплейсов в логистическую инфраструктуру, переход в начале 2019 г. Ozon и Wildberries к отдельной тарификации логистики (подписная модель) свидетельствует об изменении операционной модели маркетплейсов, дивергенции логистического и маркетингового функционалов в новых механизмах обеспечения клиентской лояльности и увеличения возвратного покупательского трафика. Используя ресурсную базу институциональных инвесторов, маркетплейсы будут более активно расширять рыночную долю, что приведет к усилению ценового демпинга и переделу рынка, ужесточению конкуренции на рынке логистики, его консолидации в более интегрированные сервисы (первая миля - фулфилмент - службы доставки), предлагающие полный цикл обработки заказов для маркетплейсов и интернет-магазинов.

Развитие сервисов и увеличение скорости доставки будут стимулировать перемещение целевого шопинга в цифровую среду с возможностью расширения практики омниканальных экспериментов. Заметим, что современная смычка стационарных каналов сбыта и онлайновых представляет собой эмпирически сложный организационный симбиоз. Его рыночная эволюция сегодня имеет реверсивный вектор развития, который в перспективе обретет более устойчивую рыночную результирующую за счет перебора более прогрессивных итераций в активно развивающейся омниканальной системе продаж [1]. Несмотря на развитие онлайн-торговли, значение стационарного сбыта остается высоким. Более того, в России и США мы наблюдаем сегодня две разнонаправленные тенденции: в России рост ритейла создает угрозу для офлайновой розницы, которая только нарастает. В США, где онлайн-ритейл имеет более длинную эволюцию, расширение омниканальных экспериментов направлено именно на то, чтобы приостановить отток трафика в онлайн.

\section{Библиографический список}

1. аспарян, В. Омниканальный ритейл в России: мифы и реальность // Retail\&Loyalty. 2015. № 7 (52). C.39.

2. Завадский M. AliExpress: переход от «модели Таobao» к «ранней версии Ттаll» в России завершен // Retail\&Loyalty. 2017. № 1 (64). С.63-65.

3. Иванов А. Российский рынок е-commerce 2016: ожидания и реальные перспективы // Retail\&Loyalty. 2016. № 3 (57). С.3-4.

4. Интернет-торговля в России 2018. По данным исследовательской компании Data Insight [Электронный ресурс].- Режим доступа: http://datainsight.ru/sites/default/files/DI_Ecommerce\%202018.pdf (дата обращения: 12.02.2019).

5. К2020 году 40\% рынка онлайн-торговли может переместиться в глобальные маркетплейсы//Retail\&Loyalty. 2015. - № 5 (50). - С. 84 .

6. Михайлюк, М.В. Логистика интернет-торговли как фактор развития многоканальных цепей поставок в системе товародвижения потребительского рынка: монография / М.В. Михайлюк; ФГБОУ ВО РГУПС. - Ростов н/Д, 2018. - 232 С.

7. Михайлюк, М.В. Трансдисциплинарный синтез и предпосылки расширения предметной области научных исследований в логистике интернет-торговли / М.В. Михайлюк // Экономика и предпринимательство. 2018. № 9.- С.275-280.

8. Рынок срочной доставки 2018. Исследование Dostavista и Data Insight [Электронный ресурс].- Режим доступа: http://www.datainsight.ru/sites/default/files/DI-Dostavista-ExpressDelivery.pdf (дата обращения: 12.02.2019).

9. Синельников В. Нестабильная система //РБК. 2019. № 3. С.108-110.

10. Щербаков В. Тенденции актуализации логистических платформ // Вестник факультета управления СПбГЭУ.-2017. - № 1-1.- С. 453-456. 